\title{
Augmented reality: Research agenda for studying the impact of its media characteristics on consumer behaviour
}

\author{
Author: \\ Ana Javornik \\ Current address: \\ University College London Interaction Centre \\ 66-72 Gower Street, WC1E 6EA, London, United Kingdom \\ Mail: a.javornik@ucl.ac.uk \\ Permanent address: \\ Institute of Marketing and Communication Management \\ Università della Svizzera italiana \\ Via Giuseppe Buffi 13, 6900 Lugano, Switzerland \\ Mail: ana.javornik@usi.ch
}




\section{Abstract:}

Augmented reality has emerged as a new interactive technology and its unprecedented way of complementing the physical environment with virtual annotations offers innovative modes for accessing commercially-relevant content. However, little is known about how consumers respond to its features. This paper approaches augmented reality (AR) by studying media characteristics of interactive technologies and shows to which extent they are indicative of current AR commercial apps. Based on a literature review about consumer responses to these characteristics, potential media effects of AR on consumer behaviour are discussed. Finally, the article proposes a research agenda for further study of this new phenomenon in marketing.

Keywords: Augmented reality, Interactive technologies, Media effects, Consumer behaviour, Human-computer interaction, Literature review 


\section{INTRODUCTION}

Augmented reality (AR) has emerged as a relevant interactive technology in the marketing environment, increasingly used in retail contexts and often developed in formats of smart device applications. Its ability to overlay the physical environment with virtual elements such as information or images, which can interact with the physical environment in real time, provides new possibilities for content delivery to consumers. It consequently holds the potential to alter a large number of consumer activities, among which information search and product trials. As its use increases, there is an ever-growing need to better understand its impact on consumer behaviour and on the experience that it delivers.

This paper proposes a research agenda for investigating consumer behaviour related to the use of AR in marketing channels, building on previous knowledge about interactive technologies and their impact on consumer behaviour. Interactive technologies have considerably transformed the way consumers engage in shopping and brand activities (Hoffman and Novak, 1996; Yadav and Pavlou, 2014). Some of the most influential changes since the evolution of web 2.0 and web 3.0 are participation in online communities (Kozinets et al., 2010), B2C and C2C interactions through social media (Kaplan and Haenlein, 2010), increased use of mobile phones and smartphone applications (Shankar and Balasubramanian, 2009; Ström et al., 2014), digital signage (Dennis et al., 2010) and engagement with immersive virtual reality (Nah et al., 2011). While challenges related to consumer responses to more established interactive technologies led the way to a rich body of research (Agarwal and Karahanna, 2000; Childers et al., 2001; Liu and Shrum, 2002; Novak et al., 2003; Pagani et al., 2011; Sheth and Solomon, 2014), the possible impact of emerging AR 
technology on consumers has only been discussed in very few cases (Huang and Liu, 2014) and, furthermore, no systematic research agenda has been proposed.

The AR industry is estimated to reach $\$ 56.8$ billion by 2020 (MarketsandMarkets, 2015), while Fortune expects it to generate $\$ 120$ billion in revenue by 2020 (Gaudiosi, 2015). Given its rise, it is progressively more important to investigate how AR affects consumer responses. With such knowledge, marketers can acquire a better understanding of how AR can be used as a tool in various shopping channels for specific purposes.

This article starts by discussing how AR functions and its current commercial applications by drawing parallels with earlier interactive technologies and their media characteristics: interactivity, hypertextuality, modality, connectivity, locationspecificity, mobility and virtuality. By studying the impact of these characteristics on consumer behaviour, we are able to propose a research agenda for future studies of AR in marketing. The agenda outlines specific directions for how research could study the specificity of these characteristics in AR - or the lack thereof -, their impact on consumer responses and the type of consumer experience they deliver in different marketing channels, such as in retail and online.

\section{THEORETICAL BACKGROUND}

AR is an interactive technology that modifies physical surroundings with superimposed virtual elements. This virtual layer, placed between the physical environments and the user, can add textual information, images, videos or other virtual items to the person's viewing of physical environment. The devices that enable such superimposition can be smartphones or tablets, wearables (head-mounted displays), fixed interactive screens or projectors (Carmigniani et al., 2011). 
AR technology has been largely investigated in the areas of computer technology and human-computer interaction, where also the most relevant definitions have been developed (presented in the Table 1).

The formulation of AR by Azuma et al. (2001), recognised as the most accepted one, emphasises not only the co-existence of virtual and real in the same space, but also interactive alignment and mutual registration of computer generated sources with physical reality. It underlines the embeddedness of AR in real time (thus deviating from virtual reality) and its interactive character. Reitmayr and Drummond (2006) added that an important element of an AR device is also its ability to be portable or wearable, thus mobile in some way. However, that applies only to some groups of AR technologies (Carmigniani et al., 2011) - fixed interactive displays for instance do not allow mobility. Overall, the focus of all the revised definitions is the augmentation of the real with the virtual layer (Van Krevelen and Poelman, 2010; Preece et al., 2015), computer-generated information (Carmigniani et al., 2011) in combination with interactivity (Van Krevelen and Poelman, 2010; Carmigniani et al., 2011; Azuma et al. 2001; Zhou et al., 2008; Reitmayr and Drummond, 2006).

The most relevant media characteristics of augmented reality as stated in these definitions are the following: interactivity, virtuality (presence of elements of virtual reality), geolocation feature / location specificity, mobility (in terms of portability and wearability) and synchronisation of virtual and physical/real (augmentation). 


\begin{tabular}{|c|c|}
\hline Authors & Definitions \\
\hline Azuma et al., 2001 & $\begin{array}{l}\text { An AR system supplements the real world with virtual } \\
\text { (computer-generated) objects that appear to coexist in the same } \\
\text { space as the real world. While many researchers broaden the } \\
\text { definition of AR beyond this vision, we define an AR system to } \\
\text { have the following properties: combines real and virtual objects } \\
\text { in a real environment; runs interactively, and in real time and } \\
\text { registers (aligns) real and virtual objects with each other. }\end{array}$ \\
\hline Zhou et al., 2008 & $\begin{array}{l}\text { Augmented Reality (AR) is a technology which allows computer } \\
\text { generated virtual imagery to exactly overlay physical objects in } \\
\text { real time. Unlike virtual reality (VR), where the user is } \\
\text { completely immersed in a virtual environment, AR allows the } \\
\text { user to interact with the virtual images using real objects in a } \\
\text { seamless way. }\end{array}$ \\
\hline $\begin{array}{l}\text { Reitmayr and } \\
\text { Drummond, } 2006\end{array}$ & $\begin{array}{l}\text { Augmented reality (AR) is a promising user interface technique } \\
\text { for mobile, wearable computing and location-based systems. }\end{array}$ \\
\hline $\begin{array}{l}\text { Van Krevelen and } \\
\text { Poelman, } 2010\end{array}$ & $\begin{array}{l}\text { Augmented reality (AR) is this technology to create a "next } \\
\text { generation, reality-based interface" and is moving from } \\
\text { laboratories around the world into various industries and } \\
\text { consumer markets. AR supplements the real world with virtual } \\
\text { (computer-generated) objects that appear to coexist in the same } \\
\text { space as the real world. }\end{array}$ \\
\hline $\begin{array}{l}\text { Carmigniani et al., } \\
2011\end{array}$ & $\begin{array}{l}\text { Augmented Reality (AR) is a real-time direct or indirect view of } \\
\text { a physical real-world environment that has been enhanced / } \\
\text { augmented by adding virtual computer-generated information } \\
\text { to it. AR is both interactive and registered in } 3 D \text { as well as } \\
\text { combines real and virtual objects. }\end{array}$ \\
\hline
\end{tabular}

Table 1: Definitions of augmented reality from computer science literature

The first forms of AR were developed in the 1950s in cinematography by Morton Heilig, who named the special cinema features "Sensorama" (Carmigniani et al., 2011). In the 1960s, Ivan Sutherland developed the first prototype of AR at Harvard that enabled viewing of 3-D graphics using a holographic projection. In the 70 s and $80 \mathrm{~s}$, research institutes, NASA, the aviation industry and other industry centres continued to develop wearable devices, digital displays and 3-D graphics with AR. Scientists Caudell and Mizell coined the term in the 1990s in the area of aviation, developing an AR assistance system for workers who were wiring harnesses (Azuma et al., 2001; Carmigniani et al., 2011). Since the 1990s, wearable computers and 
mobile AR were developed and put to use for the first time and AR has gained increased attention in computer science, linked with the areas of virtual reality, 3-D technology and mobile technology (Azuma et al., 2001; Van Krevelen and Poelman, 2010; Preece et al., 2015). The technology has also been applied in medicine, industry, gaming, military, art, navigation, education, tourism and architecture.

Initial forms of AR were not robust enough, cost-effective or sufficiently intuitive enough to be launched broadly and to have the potential of being adopted by average consumers by offering intuitiveness and ease-of-use, which are some of the crucial factors for engagement with technology (Davis et al., 1989; Pavlou, 2003). However, the conditions have changed in comparison to the 1990s when AR was still in its infancy. Technological advancement, decrease of related costs, increased mobility and portability of AR and its embeddedness in the existing digital landscape together

with geolocation applications, global positioning system (GPS) and near-field communication (NFC) have increased both the utility and consequently the relevance of AR. The current digital environment allows deployment of AR technology for marketing purposes at various touchpoints of consumer journey, especially in retail, mobile and online. The following section presents the most common AR applications in marketing at the moment, with regards to the channels where they are used and the type of augmented content they provide.

\subsection{Current uses of augmented reality in retail and mobile marketing}

In recent years, brands have been using and testing various AR apps in different contexts to examine the most suitable settings for their use. So far, AR used on smart devices and large interactive screens, either privately or publicly in retail are among the most common ones (Javornik, 2014). AR apps on smart devices allow a consumer 
for example to see a virtual product situated in the environment (such as a virtual furniture in a physical room) or to access additional digital content by scanning a product's logo or a related image (such as a scanned magazine's ad that transforms into a video on a tablet's screen). Large interactive screens on the other hand can present a greater part of the physical surrounding on the screen, to which the virtual elements are added (as for instance an AR campaign in a shopping mall with a purpose of raising consciousness about endangered species, that showed on a large screen the threatened animals that seemed to be walking around the mall).

Besides the context of use, the AR apps also differ with regard to the entities they augment (Carmigniani et al., 2011). In that sense, AR capability of enhancing the physical reality - also referred to as augmentation (Preece et al., 2015) - can overlay virtual elements on: person, products or surrounding space.

The augmentation of a person can refer either to an enhanced view of someone else or of a self. An enhanced view of another person can be for instance provided through augmented reality glasses (e.g. Google Glass or Hololens), however such applications have so far been rare in marketing due to the limited access to the head-mounted displays or goggles. On the other hand, apps for enhanced view of a self or "selfaugmentation" have been more widely disseminated in the form of virtual mirrors or virtual try-ons. While digital try-ons existed in earlier versions (websites allowed uploading a piece of apparel on one's photo or a personalised avatar), the AR virtual mirrors deliver a more realistic and interactive experience. The screen conveys a reflection of your body or of its part (for instance face, head or hand) with virtual addons, such as glasses, make-up and clothes. Virtual try-ons represent one of the more popular AR cases and have been adopted by several apparel and cosmetics brands. 
Furthermore, AR apps allow also augmentation of a product, usually by scanning an item with a smart device that can then visualise an enhanced view. Some examples of such apps are for instance those that provide additional nutritional information about food products on a shelf, show reviews as if directly linked to the products, change the colours of an item on a screen or add gaming elements.

Finally, some apps allow an augmentation of a surrounding space with virtual elements. That is used for seeing how a product would look like in a certain space (for instance a piece of furniture in the room) or for getting additional content about surrounding space (for instance the screen shows on the camera view of the street where a nearby coffee place is and which stores have a sale).

But in what way does AR act as an interactive technology? Answering that question will allow better understanding what consumer experience can AR offer.

\subsection{Augmented reality as the next interactive technology?}

Interactive technology is an umbrella term for diverse forms of computer-mediated and digital environments. Varadarajan et al. (2010) defined it as tools and devices that enable entities to engage in mediated communication and are based on digital technology, such as: e-mail, hyper-text technologies, web browsers, instant messaging, access technologies (i.e. wi-fi and GPS), mobile phones, social networking, search engines and others. Furthermore, interactive technologies share media characteristics, which are communication variables that are connected to the aspects of communication that represent an exchange and transmission of messages with various entities (Stewart and Pavlou, 2009; Littlejohn and Foss, 2008). In communication and marketing theory the term describes functional traits of technologies that permit objective, error-free measurement (Hoffman and Novak, 
1996; Sundar, 2009; Lister et al., 2008) and as such offer solid conceptual and methodological tools that allow understanding consumer responses to specific parts of experience with technology (Sundar, 2009; Pagani and Mirabello, 2011). For instance, a media characteristic telepresence represents a crucial driver for the user immersion in virtual reality (Steuer, 1992), while interactivity leads to higher involvement of a user in a computer-mediated environment (Hoffman and Novak, 1996). This approach differs from the stream that focuses on media characteristics based on subjective criteria such as social presence (Kaplan and Haenlein, 2010), media synchronicity (Dennis et al., 2008) and uses and gratifications approach (Calder et al., 2009).

The most representative media characteristics of interactive technologies are assembled in Figure 1. Only characteristics or features that can be manipulated are included, among others also to avoid proxies for interactive technologies.

\begin{tabular}{c|c}
$\begin{array}{c}\text { Media characteristics of } \\
\text { interactive technologies }\end{array}$ & Definition (author) \\
\hline Interactivity & $\begin{array}{c}\text { Machine and personal interactivity, feature-based or perceived, } \\
\text { composed of control, responsiveness and two-way communication } \\
\text { (Song and Zinkhan, 2008) }\end{array}$ \\
\hline Hypertextuality & $\begin{array}{c}\text { Potentially high number of linked sources } \\
\text { (Hoffman and Novak, 1996) }\end{array}$ \\
\hline Modality & Diversity of content representation (Sundar et al., 2012) \\
\hline Connectivity & $\begin{array}{c}\text { Technological capability of expanding and sustaining a model of } \\
\text { network, where many users can be connected among themselves } \\
\text { (Lister et al., 2008; Varadarajan et al., 2010) }\end{array}$ \\
\hline Location-specificity & $\begin{array}{c}\text { Specificity with which a technology and its user can be targeted } \\
\text { based on the precise geolocation } \\
\text { (Shankar and Balasubramanian, 2009; Varadarajan et al. 2010) }\end{array}$ \\
\hline Mobility & $\begin{array}{c}\text { Portability and wearability that allow a mobile use (Shankar and } \\
\text { Balasubramanian, 2009; Varadarajan et al., 2010) }\end{array}$ \\
\hline Virtuality & $\begin{array}{c}\text { Combination of virtual elements that causes immersion in an } \\
\text { environment constructed with computer graphics and digital video } \\
\text { (Lister et al., 2008; Blascovich and Bailenson, 2011) }\end{array}$ \\
\hline
\end{tabular}

Figure 1: Framework of interactive technologies' media characteristics

Interactivity (Steuer, 1992; Lister et al., 2008) has been extensively investigated and remains one of the core concepts for assessing digital and virtual media. Although no 
final consensus about its meaning has been reached, it is most often referred to as "...the degree to which two or more communication parties can act on each other, on the communication medium, and on the messages and the degree to which such influences are synchronized" (Liu and Shrum, 2002). Similarly, Sundar (2009) define it as "the choices provided to users and the ability to go back and forth with the interface". While interactivity is an objective feature, its link to related consumer responses is established for instance through consumer perception of how much control they view to have over a medium, to which extent it allows them to lead twoway communication and how responsive the see the medium to be (Song and Zinkhan, 2008; Sundar, 2009; van Noort et al., 2012). By definition, AR tools are also interactive as they allow communication both with other people and with the medium (Billinghurst and Kato, 2002). However, current commercial AR apps offer more features in terms of machine interactivity (i.e. allowing to access different content and interact with interface) and less so in terms of allowing augmented communication between different human parties.

Hypertextuality is a synonym and a proxy for the number of linked sources (Hoffman and Novak, 1996) and refers to the non-sequential connections among different data or navigability (Sundar, 2009) and is associated with the actions of users moving through a mediated environment and the interface that offers a large number of linked sources and different paths of how they are related together. In comparison to a standard website, current interfaces of AR view modes often don't have as many linked sources as the technology does not offer switching across so many icons as with websites, however a certain level of hypertextuality is present.

Modality refers to the types of content provided by the medium (Hoffman and Novak, 1996; Sundar, 2009) and can appear in audio and visual formats, such as music, voice 
narrative, video, images, text and others, all represent information in a different way which impacts the communication process. Content in AR apps is predominantly visual but the formats can range between 2-D or 3-D images, videos or animated content or purely textual information.

The networked character or connectivity (Hoffman and Novak, 1996) refers to the type of communication model that is considered a revolutionary trait of social media: the transformation of the one-to-one or one-to-many communication model into many-to-many models of interactions where all sides can participate in the exchange of messages and are simultaneously potential senders and receivers. While AR is often embedded in the applications that contain features for such connectivity, the AR view as such does not yet allow (at least not the current commercial applications) connectivity with as many other parties as for instance social media. However, integration with social platforms and higher connectivity is expected to be more present in the future versions.

Mobile devices represent a special category of interactive technologies because of their mobility/portability, wirelessness and location-specificity (Shankar and Balasubramanian, 2009; Varadarajan et al., 2010). Location-specificity refers to the GPS system that allows tracking of the user location through personal devices and delivering location-specific information. With $\mathrm{AR}$, location is relevant in a different way. The content delivery is not linked to the GPS position but to the elements that the camera tracks in its immediate surrounding based on which the augmented content is delivered. Some AR content is delivered without spatial tracking and just appears on the screen, seemingly fitting in the physical environment.

Portability or mobility (the characteristic of mobile devices being effortless to carry around) indicates a device's affordance for spatial dynamism (Rohm et al., 2012), 
which also included wearability (like with Apple's iWatch, FitBit or GoogleGlass). The extent to which AR is mobile, depends on the type of device it is used on. Fixed interactive screens, situated in a retail store, do not allow mobility, while smart devices can be carried around and allowing AR to be mobile, which then also affects the type of content that can be displayed based on the location.

Virtuality refers to media's capability of showing virtual elements or virtual worlds, as experienced by the user through immersion or telepresence in the environment created by computer graphics or visual elements (Lister et al., 2008; Steuer, 1992). Gaming apps, virtual worlds or virtual simulation create distinctive consumer experiences through virtual reality (Jennet et al., 2008). Virtual annotations represent an important part of AR (Billinghurst and Kato, 2002), but with an important distinction: virtual reality is separated from physical reality while AR is embedded into it. As explained in virtuality continuum (Milgram and Kishino, 1994), the reality that a user sees in virtuality, is computer generated as it does not include elements from physical surrounding on the screen (e.g. Second life). In AR, only one part of what the user sees is computer generated while the rest corresponds to physical reality and there is thus not a disconnect between the physical and the virtual. According to these criteria, AR is closer to the physical reality than the virtual reality, but has elements of virtuality.

By studying the relation of AR to the media characteristics of interactive technologies, AR can be better understood in terms of its features. Table 2 presents to which extent are these media characteristics present in the AR apps on smart devices and on fixed interactive screens, which are two of the most common AR applications in marketing. As already discussed above, AR apps posses all media characteristics of interactive technologies to some degree, however some - interactivity, virtuality, 
modality, location-specificity - are much more present and indicative of commercial AR apps than for example hypertextuality, connectivity, mobility.

\begin{tabular}{l|l|l} 
& $\begin{array}{l}\text { AR apps on smart } \\
\text { devices }\end{array}$ & $\begin{array}{l}\text { AR apps on fixed } \\
\text { interactive screens }\end{array}$ \\
\hline Interactivity & Medium to high & Medium to high \\
\hline Hypertextuality & $\begin{array}{l}\text { Few-to-many linked } \\
\text { sources }\end{array}$ & Few linked sources \\
\hline Modality & Video, Text, Image & Video, Text, Image \\
\hline Connectivity & One-to-few; Few-to-few & One-to-few, One-to-many \\
\hline Location-specificity & Medium to high & Low \\
\hline Mobility & Medium & Low \\
\hline Virtuality & Medium & Medium
\end{tabular}

Table 2: Media characteristics applied to two types of augmented reality tools

AR commercial apps at this stage do not offer high connectivity with other parties as for instance social media and are often not linked to a large number of other sources when in AR mode. While smart devices by definition allow high mobility, the AR viewing mode only permits movements to a limited extent before the AR content disappears from the visual field or from the screen. On the other hand, AR apps offer rich plethora of content modality, are often highly interactive and virtual elements are in most cases indispensable to it. The relevant question for understanding the impact of AR on consumer behaviour is how these characteristics impact shopping experience and what responses do they elicit from consumers. For that purpose we review the recent findings about consumer responses to these media characteristics based on which research agenda for AR and consumer responses is developed.

\section{METHODOLOGY}

A selected literature review about the effects of interactive technologies' media characteristics on consumer behaviour was conducted for the period between 2008 and 2014 (Table 3). 2008 was used as a cut off because similar reviews were done or the period prior to 2008 (Dennis et al., 2008; Varadarajan et al., 2010; Voorveld et al., 
2009; Hoffman and Novak, 2009; Ström et al., 2014). References to them are made throughout the study in order to build on the previously established knowledge. The review serves as a basis for derivation of research directions relating to consumer responses to $\mathrm{AR}$ in marketing.

The search was performed on Google Scholar and ABI/Inform by using the keywords: consumer behaviour and the above assembled media characteristics (interactivity, hypertextuality, virtuality etc). If keywords yielded too few results, other related keywords were used such as browsing in the case of hypertextuality. Only articles with quantitative studies were taken into account, as the main focus was to survey measured consumer responses to media characteristics. Such an approach towards a literature review (classification based on technologies' effects on users) has been conducted in previous reviews (Varadarajan et al., 2010; Voorveld et al., 2009). The aim was to assemble at least 5 highly cited articles per characteristic. Final number of the articles selected for the review was 44 . For each study, we classified consumer responses according to the media characteristics. 3 articles were used for two categories, the other 41 relate to only one category.

\section{LITERATURE REVIEW ON CONSUMER RESPONSES TO MEDIA}

\section{CHARACTERISTICS OF INTERACTIVE TECHNOLOGIES}

One of the most consistently confirmed effects of interactivity is flow (Chang and Wang, 2008; van Noort et al., 2009; Hoffman and Novak, 2009), which refers to immersion of consumers into the highly absorbing state when using interactive features allowing communication either with machine or other people, supported by challenge and sense of control (Csikszentmihalyi, 1997). Flow can improve learning, establish perceived behavioural control, increase exploratory and participatory behaviour and create positive subjective experiences and distortion in time perception, 
but it can also cause a distraction from the original task and physical and mental fatigue (Hoffman and Novak, 2009). With time, the relevance of certain constructs change - user skill and perceived utility become more relevant with continuous web experience, while challenge, attention and exploratory behaviour decrease (Novak et al., 2000), which suggests that with longer use of the web technologies, attention is placed more on skill-based, goal-directed activities than on the experiential ones (Novak et al., 2003). Flow caused by interactivity can act as a mediator for consumer responses such as brand and website attitude (Chang and Wang, 2008; Song and Zinkhan, 2008; Gao et al., 2009; van Noort et al., 2012), cognitive responses (van Noort et al., 2012), behavioural intentions to use the website again in the future (Sundar et al., 2012; van Noort et al., 2012) and purchase intentions (van Noort et al., 2012; Chang and Wang, 2008; Huang, 2012). Interactivity was found to also lead to loyalty (Song and Zinkhan, 2008; Cyr et al., 2009) and trust (Cyr et al., 2009; Chu and Yuan, 2013). Other factors such as the quality of the message and the type of a task (complaining vs. search) significantly impact consumer perception of interactivity (Song and Zinkhan, 2008). However, while there have been solid results confirming that interactivity leads to affective responses (van Noort et al., 2012; Huang, 2012; Gao et al., 2009; Chang and Wang, 2008), there is less evidence for it to result in more cognitive involvement for which some studies report positive effect (van Noort et al., 2012; Cyr et al., 2009) and others lack thereof (Huang, 2012). There are also contradictory findings with regards to purchase intentions if they are significantly affected by perceived interactivity or not (van Noort et al., 2012; Chu and Yuan, 2013). Finally, different types of interactivity (e.g. medium, modality and source interactivity), relate to diverse consumer responses (e.g. perceived control, responsiveness and two-way communication) (Sundar et al., 2014). 


\begin{tabular}{|c|c|c|}
\hline $\begin{array}{l}\text { Media } \\
\text { characteristic }\end{array}$ & Relevant literature & $\begin{array}{c}\text { Consumer responses brought forward by the } \\
\text { characteristic }\end{array}$ \\
\hline \multirow[t]{8}{*}{ Interactivity } & Song and Zinkhan, 2008 & $\begin{array}{c}\text { Mediates website effects on satisfaction, loyalty, } \\
\text { perceived quality, WOM and purchase behavior }\end{array}$ \\
\hline & Chang and Wang, 2008 & Flow, Positive website attitude; Future use intentions \\
\hline & Cyr et al., 2009 & E-loyalty; Enjoyment; Efficiency, Trust \\
\hline & Gao et al., 2009 & Positive attitude towards mobile ad \\
\hline & Huang, 2012 & Affective involvement; Flow \\
\hline & van Noort et al., 2012 & $\begin{array}{l}\text { Flow, Affective (brand \& website attitude) and } \\
\text { cognitive responses (related thoughts), Behavioral } \\
\text { intentions }\end{array}$ \\
\hline & Chu and Yuan, 2013 & Positive website attitude; E-Trust \\
\hline & Sundar et al., 2014 & Positive website attitude; Intention for future use \\
\hline \multirow[t]{5}{*}{ Hypertextuality } & $\mathrm{Su}, 2008$ & $\begin{array}{l}\text { Complex search on sites or across sites leads to lower } \\
\text { search for product information and price }\end{array}$ \\
\hline & Parra and Ruiz, 2009 & $\begin{array}{l}\text { Navigation leads to smaller consideration sets, } \\
\text { especially under higher information load }\end{array}$ \\
\hline & Richard et al., 2010 & $\begin{array}{l}\text { Exploratory behavior and consequently to positive } \\
\text { website attitude and involvement. }\end{array}$ \\
\hline & $\begin{array}{l}\text { Flavian-Blanco et al., } \\
2011\end{array}$ & $\begin{array}{l}\text { Effort and positive emotions during the online search } \\
\text { positively impact positive attitude after the search }\end{array}$ \\
\hline & Park et al., 2012 & $\begin{array}{l}\text { Hedonic browsing correlates with impulse buying, but } \\
\text { the utilitarian browsing correlates to it negatively }\end{array}$ \\
\hline \multirow[t]{8}{*}{ Modality } & Park et al., 2008 & $\begin{array}{l}\text { Product rotation } \Rightarrow \text { Cognitive response (perceived } \\
\text { information), Affective response (mood, attitude), } \\
\text { Behavioral intentions. }\end{array}$ \\
\hline & Kim and Lennon, 2008 & $\begin{array}{l}\text { Verbal \& visual information affect brand attitude and } \\
\text { knowledge, but verbal representations exhibit } \\
\text { superior effects on purchase intentions. }\end{array}$ \\
\hline & Jin, 2009 & $\begin{array}{l}\text { Positive brand and product attitude; Purchase } \\
\text { intentions (for consumers with high involvement) }\end{array}$ \\
\hline & Goel and Prokopec, 2009 & $\begin{array}{l}\text { Less rich media (website) leads to higher trust, product } \\
\text { diagnosticity and informativenes than } 3 \mathrm{D} \text { world }\end{array}$ \\
\hline & Lin et al., 2012 & $\begin{array}{l}\text { Visual information impact e-Wom perceived message } \\
\text { quality, credibility, interest, purchase intentions }\end{array}$ \\
\hline & Hsieh et al., 2012 & $\begin{array}{l}\text { Visually and acoustically richer media lead to more } \\
\text { positive attitude and higher eWom }\end{array}$ \\
\hline & Li and Meshkova, 2013 & $\begin{array}{l}\text { Richer media increase informativeness and purchase } \\
\text { intention for both search and experience product. }\end{array}$ \\
\hline & $\begin{array}{l}\text { Huang and Hsu Liu, } \\
2014\end{array}$ & $\begin{array}{l}\text { Rich media with storytelling have stronger impact on } \\
\text { consumer responses than those without narration }\end{array}$ \\
\hline \multirow[t]{6}{*}{ Connectivity } & Calder et al., 2009 & Positive attitude towards the ad and intention to click. \\
\hline & Chan and Li, 2010 & $\begin{array}{l}\text { Individual enjoyment acts as a strong predictor of } \\
\text { community reciprocity and commitment. }\end{array}$ \\
\hline & Pagani et al., 2011 & Social engagement leads to more active medium usage \\
\hline & Huang, 2012 & $\begin{array}{l}\text { Social identity impacts flow, involvement and } \\
\text { commitment. }\end{array}$ \\
\hline & Laroche et al., 2012 & $\begin{array}{l}\text { Community connectivity leads to brand use, trust and } \\
\text { loyalty }\end{array}$ \\
\hline & Pescher et al., 2014 & $\begin{array}{l}\text { Tie strength leads to higher influence, but users with } \\
\text { weak ties are more likely recommending an ad. }\end{array}$ \\
\hline \multirow[t]{4}{*}{$\frac{\text { Location- }}{\text { specificity }}$} & Xu et al., 2009 & $\begin{array}{l}\text { Location-based advertising leads to positive attitude, } \\
\text { intention to use and purchase, but also to irritation }\end{array}$ \\
\hline & Gao et al., 2009; & $\begin{array}{l}\text { Customization of brand communication significantly } \\
\text { impacts the perceived interactivity and flow, } \\
\text { attitude and purchase intentions. }\end{array}$ \\
\hline & Xu et al., 2011 & $\begin{array}{l}\text { Benefits of personalization can override privacy } \\
\text { concern in some contexts }\end{array}$ \\
\hline & Zhou, 2013 & $\begin{array}{l}\text { Contextual offerings lead to flow and higher trust, } \\
\text { which impacts further usage intention. }\end{array}$ \\
\hline
\end{tabular}




\begin{tabular}{|c|c|c|}
\hline & Luo et al., 2014 & $\begin{array}{l}\text { Advertising at specific location significantly increases } \\
\text { customer willingness to purchase. }\end{array}$ \\
\hline \multirow[t]{5}{*}{ Mobility } & Sultan et al., 2009 & $\begin{array}{l}\text { Increased mobile activity leads to higher willingness } \\
\text { to provide information and access content. }\end{array}$ \\
\hline & $\begin{array}{l}\text { Dickinger \& Kleijnen, } \\
2009\end{array}$ & $\begin{array}{l}\text { Mobile advertising leads to privacy concern and lack } \\
\text { of perceived control }\end{array}$ \\
\hline & $\begin{array}{l}\text { Kowatsch \& Maass, } \\
2010\end{array}$ & $\begin{array}{l}\text { If mobile recommender agent is useful, consumers } \\
\text { intend to us it in the future }\end{array}$ \\
\hline & Rohm et al., 2012 & $\begin{array}{l}\text { Mobile marketing can lead to positive attitude when } \\
\text { perceived usefulness, personal innovativeness and } \\
\text { attachment are high }\end{array}$ \\
\hline & Bart et al., 2014 & $\begin{array}{l}\text { Impact of mobile displayed advertising on product } \\
\text { attitude and purchase intentions depends on the } \\
\text { type of product and on prior product knowledge. }\end{array}$ \\
\hline \multirow[t]{10}{*}{ Virtuality } & Daugherty et al., 2008 & $\begin{array}{l}\text { Higher product knowledge, brand attitude and } \\
\text { purchase intentions (in comparison to magazine). }\end{array}$ \\
\hline & Lee and Chung, 2008 & $\begin{array}{l}\text { Stronger quality assurance and enjoyment in virtual } \\
\text { shopping hall in comparison to ordinary mall. }\end{array}$ \\
\hline & Kim and Forsythe, 2008 & $\begin{array}{l}3 \mathrm{D} \text { view is perceived easier to use than } 2 \mathrm{D} \text { and virtual } \\
\text { try-on, but virtual try-on is more entertaining. }\end{array}$ \\
\hline & Goel and Prokopec, 2009 & $\begin{array}{l}\text { Lower informativeness, trust and product diagnosticity } \\
\text { than on websites. }\end{array}$ \\
\hline & Jin and Bolebruch, 2009 & $\begin{array}{l}\text { Increased product involvement and product attitude } \\
\text { with spokes-avatar advertising. }\end{array}$ \\
\hline & Gabisch, 2011 & $\begin{array}{l}\text { Stronger impact of virtuality on purchase when higher } \\
\text { perceived diagnosticity and self-congruence. }\end{array}$ \\
\hline & Nah et al., 2011 & $\begin{array}{l}\text { 3D induces greater sense of enjoyment and } \\
\text { telepresence than } 2 \mathrm{D} \text { environment. }\end{array}$ \\
\hline & Merle et al., 2012 & $\begin{array}{c}\text { Personalized virtual try-on leads to higher hedonic and } \\
\text { utilitarian value than non-personalized try-on. }\end{array}$ \\
\hline & Huang and Liu, 2014 & $\begin{array}{l}\text { Rich virtual media have a significantly higher impact } \\
\text { on ROI, reported aesthetics, playfulness and } \\
\text { reported excellence when narrated. }\end{array}$ \\
\hline & Huang and Liao, 2014 & $\begin{array}{l}\text { Presence, playfulness, reported aesthetics, usefulness } \\
\text { and behavioral intentions. }\end{array}$ \\
\hline
\end{tabular}

Table 3: Literature review about effects of interactive technologies and their media characteristics on consumer behaviour for the period 2008 - 2014

Hypertextuality has been largely investigated in the frame of navigability, i.e. users'

navigation and search across different sources of content, which can result in exploration of the myriad of different links and sources on their devices (Hoffman and Novak, 2009). Richard et al. (2010) found that the drivers differ across gender - men are more likely to explore based on their skills, while women are more motivated by the challenge, however in both cases such exploration leads to a more positive attitude towards the site and involvement with it. Affective states and perceptions experienced during the explorations positively impact the post-search activities and emotional states (Flavian-Blanco et al., 2011) and entertaining content is a stronger predictor for site involvement and exploration than effectiveness of information content (Richard et 
al., 2010). Consumers are more willing to search for different types of information when search is made easy both within sites or across sites (Su, 2008) and higher information load and search allows them to narrow consideration sets of products they want to consider (Parra and Ruiz, 2008). Finally, Park et al. (2012) show that the purpose for browsing leads to different purchase behaviour - hedonic browsing can result in impulse buying, while the utilitarian browsing decreases the possibility.

The different types of information representation or modality - visual, verbal, audio, video - elicit different responses from consumers. Psychology research established paradigm about dominance of visual cues' effects on memory and attitude in comparison to the verbal ones (Childers and Houston, 1984). Marketing research shows that richer online information creates more positive responses (Lin et al., 2012; Hsieh et al., 2012) and even increased willingness to pay (Li and Meshkova, 2013). Visual cues as opposed to the verbal ones lead to higher credibility of eWom and its perceived quality, as well as to higher interest in a product and purchase intentions (Lin et al., 2012). Also, richer visual and sound effects in video ad impact consumers' positive attitudes and willingness to share such a video (Hsieh et al., 2012). Furthermore, the product category plays an important difference. For search and hedonic product visual information delivers a satisfying comprehension of a product, while some utilitarian products require additional verbal information (Lin et al., 2012). Richness in modality contributes to the formation of more positive attitudes towards a brand and related products and consequently more intense purchase intentions (Jin, 2009). Such an effect is significant for consumers with lower prior involvement, while the ones with higher prior involvement are not significantly more affected by the richer 3D environment (Jin, 2009). While consumer responses can become more intense with higher media richness, a presence of narration, cause-effect 
and storytelling in virtual and augmented reality experience reveals even stronger impact on consumer ROI, playfulness and perception of service quality in comparison to rich media without narrative elements (Huang \& Hsu Liu, 2014).

However, a study by Kim and Lennon (2008) presented contrary findings, i.e. that effects of online verbal representation as opposed to the visual one were found to have a stronger impact on brand knowledge, attitude and purchase intentions. Also, Goel and Prokopec (2008) showed that despite the fact that virtual worlds offer a richer media, websites are significantly better in establishing trust, informativeness and product diagnosticity, as they offer more information.

Connectivity between brands and consumers in social networks is high and all consumers, not just brands, are potential influencers, depending on their reach, influence and credibility (Hanna et al., 2011; Pescher et al., 2011). The embeddedness of users in social networks and social identity has a strong impact on consumers' flow and involvement with a certain website (Huang, 2012). Social-interactive engagement, for instance, leads to a positive attitude towards the ad and thus a greater probability of the user clicking on it (Calder et al., 2009), to reciprocity behaviour to other members (Chan and Li, 2010;) and to more active contribution to the content on social media in comparison to a non-social engagement (Pagani and Mirabello, 2011). Also, the most influential recommendations are made through strong ties (Pescher et al., 2011).

The location-specificity allows for geolocation and personalisation, enabling marketers to deliver a more precise and tailor-made messages to consumers, which leads to more positive attitude, higher intention to purchase and higher trust (Zhou, 2013; Xu et al., 2009; Gao et al., 2009, Luo et al., 2014). However, privacy represents a high concern (Xu et al., 2011; Zhou, 2013) that can act as detrimental to the 
advantage of the location-specific marketing messages (Xu et al., 2013). Accuracy in terms of location-specificity requires precise knowledge of spatial proximity in order to time the marketing messages efficiently (Luo et al., 2014).

While mobility represents a significant advantage and can deliver solutions at the exact time and place where needed, acceptance and effectiveness of mobile marketing communications face an obstacle related to privacy concerns (Sultan et al., 2009; Dickinger and Kleijnen, 2009; Ström et al., 2014). But once consumers start using a mobile device for commercial purposes, they report intentions to use it again in the future (Sultan et al., 2009; Kowatsch and Maass, 2010) and develop positive attitudes towards it (Rohm et al., 2012), especially when the activity was perceived useful (Kowatsch \& Maass, 2010; Rohm et al., 2012). Personal characteristics such as innovativeness and tech-savviness play a strong role with adopting smart phones for shopping purposes in retail (Ström et al., 2014; Rohm et al., 2012). There also exist substantial differences in responses to promotion of utilitarian and hedonic products, as mobile advertising works better for utilitarian products (Bart et al., 2014), while Pescher et al. (2013) showed that entertainment value has reportedly a stronger impact in the decision-making process. There exists a common agreement that the value of device mobility is perceived highest when integrated in the existing consumer journey (Ström et al., 2014).

Virtuality typically causes sensation of immersion or telepresence, where one feels detached from a physical reality and absorbed by the activities on the screen and the virtual elements on it (Jennett et al., 2008; Animesh et al., 2011; Nah et al., 2011, Faiola et al., 2013). Surprisingly, the level of enjoyment can be higher in virtual shopping malls than in real, physical ones (Lee and Chung, 2008). A 3D environment, which is richer in comparison to the $2 \mathrm{D}$ one, has been proven to lead to stronger 
enjoyment (Nah et al., 2011) and, furthermore, virtual try-on technology provides a stronger entertainment value of the shopping experience than $2 \mathrm{D}$ or $3 \mathrm{D}$ rotations and exhibits a stronger hedonic role (Kim and Forsythe, 2008). A virtual experience positively impacts consumer intentions towards the purchase (Jin 2009, Gabisch 2011) and willingness to pay for both search and experience products, however excitement is higher for experience products, especially for female consumers (Li and Meshkova, 2013).

Types of virtuality can be different - either the entire world on the screen is represented as virtual (like Second life or virtual games) or there are only separated virtual elements, like for instance avatars or virtual try-ons. While the virtual worlds create a strong immersive experience (Animesh et al., 2011), spokesavatar contributes to a positive shopping experience by increasing the product involvement and product attitude to a significantly higher level than unimodal audio messages (Jin and Bolebruch, 2009).

Virtual try-ons allow consumers to see a simulation of how a certain product would look like on a person, for instance on a generic avatar or a personalised model (Kim and Forsythe, 2008; Cho and Schwarz, 2012; Merle et al., 2012). They are generally related with a high entertainment/hedonic value (Kim and Forsythe, 2008), but contrary to that Merle et al. (2012) show that virtual try-on display higher utilitarian value with respect to $2 \mathrm{D}$ and $3 \mathrm{D}$ product simulation. Other $3-\mathrm{D}$ technologies were proven to perform both a functional and hedonic role in the purchase process (Kim and Forsythe, 2008). Product rotation is also a type of a visual simulation that creates a sense of telepresence and impacts both cognitive and affective responses towards a product and leads to behavioural intentions (Nah et al., 2011; Park et al., 2008). Daugherty et al. (2008) have shown that both virtual and direct experience with a 
product leads to the same brand attitude and purchase intention, but the virtual experience provides better brand knowledge (cognitive response) than the direct experience.

While a typical website cannot always provide a sense of direct experience with a product, the virtual product simulations have the potential to overcome the shortcoming of the lack of a physical presence on websites. On the other hand, trust towards the virtual store is lower in comparison to the websites, as the novelty of virtual world being utilised as a shopping channel creates a negative impact (Kim and Forsythe, 2008; Goel and Prokopec, 2009). Finally, personal characteristics such as cognitive involvement (Kim and Forsythe, 2008; Huang and Liao, 2014) and selfcongruence (Gabisch, 2011) also display impacts on the relationships between virtual features and consumer responses.

\section{RESEARCH AGENDA FOR STUDYING CONSUMER RESPONSES TO}

\section{AUGMENTED REALITY}

The review provided a framework within which the impact of AR different characteristics on consumer behaviour can be discussed. In the continuation, we therefore examine these relations in-depth and propose directions for how to advance this knowledge in future research.

Research on interactivity has shown this feature is strongly linked to flow and that it represents a driver for numerous affective responses as well as some behavioural and cognitive ones. Future studies should thus explore if that is the case also for interactivity in $\mathrm{AR}$ and if flow constitutes a core part of the experience with that technology. To which extent do the correlates of interactivity - such as perceived control, responsiveness and two-way communication (Sundar et al., 2015) - also 
represent part of the experience with AR and does interactivity in AR exist in other forms given that its modus operandi goes beyond the screen and interacts with the space? As the two-way communication is not yet a salient feature of current commercial AR modes and the interaction is focused on augmenting the surrounding space, it is not clear how that affects consumer experience with AR. To which extent does the interactivity represent a driver for affective responses (e.g. product and brand attitude), for cognitive responses (e.g. brand knowledge and recall) and behaviour or behavioural intentions (e.g. word-of-mouth, revisit and purchase)? If previous studies on interactivity showed that the consumer experience is in many cases predominantly impacted by affective drivers, to which extent is that true also for AR and what is the role of cognitive factors? Is consumer experience with AR principally hedonic and serving as an entertainment tool or is it used for utilitarian purposes? Does that change over time when consumer gets more used to the technology and thus focuses less on exploration and more on goal-oriented behaviour (Hoffman and Novak, 2009)?

High number of linked sources - hypertextuality - allows for involvement in web exploration and browsing. Given that current AR apps offer less links to other sources and focus more on the immediate physical points that can be digitally augmented, it is important to understand if that represents a disadvantage for consumers. Should future AR apps be embedded to a higher level with other social media platforms and would that display a significant impact on consumer experience with AR? Would the linked sources have a similar impact on decision-making as they have shown to have in the web studies - for instance by narrowing down the consideration set of products and, supported by other linked content, encourage consumers to explore more of the related material? 
How do different modalities in AR - video, audio, text, image - yield different consumer responses? Dominant belief in psychology has established supremacy of visual information in terms of its impact on attitudes and knowledge in comparison to the textual cues. Given that AR mode visually displays some part of the surrounding on the screen, future studies need to investigate what modality combines best with the camera view of physical environment for the most well received response: text that adds information directly to the specific elements, imagery that modifies or enhances some part of the surrounding or videos that directly augment the physical elements? Are there specific combinations that work better for certain types of tasks / contexts / products / experiences?

Connectivity is less enabled in current AR apps in comparison to social media. Given that the forms of online and offline social engagement display a strong value and drive consumer involvement, positive attitude and content contribution, relevant research question is how does the potential lack of connectivity influence consumer experience? Will the future AR apps develop more into that direction?

Numerous AR apps are location-specific, given that much of the AR content is delivered when the camera tracks a certain object, target, location. That can make some AR apps highly relevant for retail, as the AR content would appear on a person's smart devices when tracking pre-defined points in the stores. Privacy concerns with AR on smart devices will likely represent less of an issue, as the AR content is delivered based on pull and not push communication and therefore perceived as less intrusive. Will the AR apps that are linked to a location, be viewed as a tool of highly personalised customer service delivery and thus lead to more positive attitude, purchase intentions and higher trust, as is the case with other location-specific interactive technologies? Will such impacts diminish with AR apps 
that are not location-specific, such as for instance virtual try-on? Furthermore, the apps that are not linked to a specific location and can deliver the AR content anywhere, are likely to provide the advantages of mobility, therefore allowing a tailormade solution at the exact time and place defined by consumer. Virtual try-ons or product simulations shown on smart devices are accessible at one's fingertips and if consumers perceive them useful, they are likely to use them again and develop positive attitude towards the app as was the case with other technologies, however future research needs to test these assumptions. Some retailers may offer their AR apps only in the store on fixed interactive screens that do not allow mobility. Would that represent a disadvantage? The success of such applications may rely heavily on how they are integrated in consumer journey and the extent to which they support other marketing activities.

Immersion and telepresence are one of the most often recorded consumer responses to virtuality. Given that AR possesses some of its elements, but differs from it by being much closer to the physical environment, one of the most crucial future research foci would be to determine the difference in consumer responses to the two environments and compare the advantage and disadvantages of the two. Research on virtual reality in consumer studies also discovered that enjoyment and experiential value have a strong impact on consumer behaviour in virtual environments (Kim and Forsythe, 2008; Chan and Li, 2010; Huang and Liu, 2014) while that is not always the case for utilitarian or purposive value and that the related affective commitment is a stronger predictor of behavioural intentions than cognitive commitment (Huang, 2012), which is also the case for interactions on website (van Noort et al., 2012). Future research on AR should explain if affective commitment and experiential value are of a higher relevance and a stronger motivator for consumers to get engaged with it than the 
rational, cognitive commitment and the pursuit of more utilitarian values. Will the difference between consumer cognitive and affective responses become even more noticeable in using AR technologies, given the AR potential for creating an entertaining consumer experience? To which extent do the underlying reasons for these differences depend on the tasks consumers pursue in their engagement with the technology, the type of goods they are interested in (search vs. experience goods) or personal characteristics (such as cognitive innovativeness)? Furthermore, virtual models and simulations led to high product involvements, which can lead to assumption that AR virtual try-ons will bring the same. How will that depend on the type of product and contexts of trial (retail vs. home)? Also, given that trust was lower for virtual environments in comparison to ordinary websites, will trust represent an issue also for product involvement and purchasing behaviour with AR apps? Will that depend on the amount and quality of supporting information that will be available to consumers in addition?

Furthermore, there are other crucial issues that arose from the review and are related more to the specificities of AR. Given that AR technology represents a recent form of interaction, what role does a user's technological savviness and cognitive innovativeness/ openness to novelty play in adoption of AR-based tools and with what rate are AR marketing apps actually being used and adopted for shopping activities? Because of its technological advancement, AR often elicits a fascination, a so-called "wow" effect. How do consumer interactions with AR change when they get used to it and the initial magic disappears? Will goal-oriented behaviour progressively become more important than the exploratory one, especially when appropriate skills are adopted, as was the case for web behaviour (Hoffman and Novak, 2009)? 
One of the most important emphases should be placed on investigating the uniqueness of AR technology, i.e. its ability to overlay the physical environment or some part of it with virtual images or information, which makes AR apps interacting with physical space and significantly distinguishes AR from virtual reality. Human-computer interaction field names this characteristic as augmentation (Billinghurst and Kato, 2002; Preece et al., 2015). Further research is needed to conceptualise and operationalise this characteristic and to understand what type of consumer experience it creates. How exactly users are drawn into this new form of reality and what effects it has on them has not yet been exploited in consumer behaviour literature.

Given that there exists a noticeable heterogeneity across AR tools and that new forms are expected to emerge, the next step is to investigate if differences exist in consumer responses across AR tools, keeping other confounding variables constant. For instance, what would be the alteration (if any) in consumer responses to an AR app on a fixed public interactive screen in comparison to the same app on his or her individual device? Would there be a change in response between an AR app on a wearable/portable device in comparison to the same app on a smartphone? How does the device and the size of the screen (smartphone vs. tablet vs. large screen) impact the experience?

Finally, with regards to the methods, most of the studies base their findings on experimental design with students or other invited participants, which results in nonvoluntary exposure to the manipulation check (Voorveld et al., 2010). While such research designs allow high control of user activities and high internal validity, this does not accurately capture the effect of contextual factors, of other possible moderators and the difference between "non-voluntary" technology exposure and intentional usage. Human interaction with technology is highly dependent on contexts 
and on external factors that are not replicated in the lab studies, which is why studies "in-the-wild" (Rogers, 2012) are of relevance as they offer in-depth insights into use of technology and increase external validity. Also, they reveal a larger part of consumer journey as they investigate interactions in context and thus reach beyond isolated episodes.

\section{CONCLUSION}

The present study approaches the largely unexplored subject of AR in marketing and discusses the consumer responses that this technology can potentially elicit. It does so by studying salient media characteristics of interactive technologies, applying them to two prominent AR formats in marketing: smart device apps and large interactive screens. By conducting a literature review on consumer responses to media characteristics, and combining this with current knowledge about AR, numerous directions for future research emerge.

Firstly, while most AR apps have an interactive character, the AR interactivity is predominantly machine- and space-related and less associated with two-way communication, which is typical for web and mobile interactivity. Interactivity in AR may thus possibly lead to consumer responses that differ from responses to web interactivity. Furthermore, connectivity is less present in AR apps, which can cause an absence of responses that are associated with social-interactive engagement. Location-specificity and mobility on the other hand are symptomatic of AR, which typically ensures customised or convenient customer service. Future studies will demonstrate whether this translates to higher willingness of future use and positive attitude, as it has been the case for mobile technology. 
This study suggests that AR differs from other interactive technologies in its so-called augmentation, arguably its defining characteristic, which refers to its ability to overlay physical environments with virtual elements. The proximity of virtual elements with physical space, seamlessness of real and simulated and augmentation of the user's surrounding elements are concepts that have not yet been investigated in detail in marketing theory. Further conceptualisation and operationalisation of this characteristic is required, as well as empirical testing of its relations with consumer responses.

AR-related studies should also aim to reach beyond separated consumer responses and investigate the consumer experience as a whole. Previous research, for instance, shows that some of the interactive technologies can be highly immersive, as is the case for virtual reality. Future studies need to investigate to which extent the immersion defines AR consumer experience, given that $\mathrm{AR}$ possesses some traits of virtual technologies, but also differs from it in the sense that it does not create a disruption between the physical and virtual world. Furthermore, the research agenda proposes that consumer experience with AR might be more hedonic than utilitarian, especially during the initial episodes with the technology, and that the affective component plays a stronger role in leading to the behavioural responses than the cognitive. Such assumptions are based on the findings from previous research and need to be tested empirically in future studies.

More in-depth investigation of this new form of human-computer interaction is clearly required (Yadav and Pavlou, 2014). It brings with it significant challenges for consumer studies and makes the case for further investigation of the questions evoked above. Answers to these would expand upon our existing knowledge about consumer 
responses to interactive technologies and would allow marketers to design AR campaigns more efficiently and avoiding gimmicky applications.

As AR technology in marketing is currently evolving at high speed, future developments will likely go in different directions, also to some that have not been mentioned in this work. However, hopefully this paper offers insight into some of the current advances of $\mathrm{AR}$ and the type of consumer responses this technology will incite.

ACKNOWLEDGEMENTS

The author would like to thank the Swiss National Science Foundation which supported this project through the Doc.mobility Fellowship grant scheme. Furthermore, the author would also like to thank Prof. Ivan Snehota, Prof. Margherita Pagani and Prof. Michael R. Solomon for their invaluable comments and feedback on the earlier versions of this article, as well as Dr. Morgan Harvey and Marta Pizzetti for their revision and proof reading. 


\section{REFERENCES}

1. Agarwal, R., Karahanna, E., 2000. Time flies when you're having fun: Cognitive absorption and beliefs about information technology usage. MIS Q. 24, 665-694.

2. Animesh, A., Pinsonneault, A., Yang, S.-B., Oh, W., 2011. An Odyssey into Virtual Worlds: Exploring the Impacts of Technological and Spatial Environments on Intention to Purchase Virtual Products. MIS Q. 35, 789-810.

3. Azuma, R., Behringer, R., Julier, S., Macintyre, B., 2001. Recent Advances in Augmented Reality. IEEE Comput. Graph. Appl. 21, 34-47.

4. Bart, Y., Stephen, A.T., Sarvary, M., 2014. Which Products Are Best Suited to Mobile Advertising? A Field Study of Mobile Display Advertising Effects on Consumer Attitudes and Intentions. J. Mark. Res. 51, 270-285. doi:10.1509/jmr.13.0503

5. Billinghurst, M., Kato, H., 2002. Collaborative augmented reality. Commun. ACM 45, 64-70. doi:10.1145/514236.514265

6. Blascovich, J., Bailenson, J., 2011. Infinite reality: Avatars, eternal life, new worlds, and the dawn of the virtual revolution. William Morrow \& Co.

7. Calder, B.J., Malthouse, E.C., Schaedel, U., 2009. An Experimental Study of the Relationship between Online Engagement and Advertising Effectiveness. J. Interact. Mark. 23, 321-331. doi:10.1016/j.intmar.2009.07.002

8. Carmigniani, J., Furht, B., Anisetti, M., Ceravolo, P., Damiani, E., Ivkovic, M., 2011. Augmented reality technologies, systems and applications. Multimed. Tools Appl. 51, 341377. doi:10.1007/s11042-010-0660-6

9. Chan, K.W., Li, S.Y., 2010. Understanding consumer-to-consumer interactions in virtual communities: The salience of reciprocity. J. Bus. Res. 63, 1033-1040. doi:10.1016/j.jbusres.2008.08.009

10. Chang, H.H., Wang, I.C., 2008. An investigation of user communication behavior in computer mediated environments. Comput. Human Behav. 24, 2336-2356. doi:10.1016/j.chb.2008.01.001

11. Childers, T.L., Carr, C.L., Peck, J., Carson, S., 2001. Hedonic and utilitarian motivations for online retail shopping behavior. J. Retail. 77, 511-535. doi:10.1016/S0022-4359(01)00056-2

12. Childers, T.L., Houston, M.J., Houstonw, J., 1984. Conditions Effect on for a Memory Consumer. J. Consum. Res. Inc. 11, 643-654.

13. Cho, H., Schwarz, N., 2012. I Like Your Product When I Like My Photo: Misattribution Using Interactive Virtual Mirrors. J. Interact. Mark. 26, 235-243. doi:10.1016/j.intmar.2012.03.003

14. Chu, K.-M., Yuan, B.J.C., 2013. The Effects of Perceived Interactivity on E-Trust and EConsumer Behaviors: The Application of Fuzzy Linguistic Scale. J. Electron. Commer. Res. $14,124-137$.

15. Csikszentmihalyi, M., 1997. Finding flow: The psychology of engagement with everyday life. Basic Books.

16. Cyr, D., Head, M., Ivanov, A., 2009. Perceived interactivity leading to e-loyalty: Development of a model for cognitive-affective user responses. Int. J. Hum. Comput. Stud. 67, 850-869. doi:10.1016/j.ijhcs.2009.07.004

17. Daugherty, T., Li, H., Biocca, F., 2008. Consumer Learning and the Effects of Virtual Experience Relative to Indirect and Direct Product Experience. Psychol. Mark. 25, 568-586. doi:10.1002/mar

18. Davis, F.D., Bagozzi, R.P., Warshaw, P.R., 1989. User Acceptance of Computer Technology: A Comparison of Two Theoretical Models. Manage. Sci. 35, 982-1003. doi:10.1287/mnsc.35.8.982

19. Dennis, A.R., Fuller, R.M., Valacich, J.S., 2008. Media, tasks and communication processes: A theory of media synchronicity. MIS Q. 32, 575-600.

20. Dennis, C., Merrilees, B., Jayawardhena, C., Wright, L.T., 2009. E-consumer behaviour. Eur. J. Mark. 43, 1121-1139. doi:10.1108/03090560910976393

21. Dennis, C., Newman, A., Michon, R., Josko Brakus, J., Tiu Wright, L., 2010. The mediating effects of perception and emotion: Digital signage in mall atmospherics. J. Retail. Consum. Serv. 17, 205-215. doi:10.1016/j.jretconser.2010.03.009

22. Dickinger, A., Kleijnen, M., 2008. Coupons going wireless: Determinants of consumer intentions to redeem mobile coupons. J. Interact. Mark. 22, 23-39. doi:10.1002/dir.20115 
23. Faiola, A., Newlon, C., Pfaff, M., Smyslova, O., 2013. Correlating the effects of flow and telepresence in virtual worlds: Enhancing our understanding of user behavior in game-based learning. Comput. Human Behav. 29, 1113-1121. doi:10.1016/j.chb.2012.10.003

24. Flavián-Blanco, C., Gurrea-Sarasa, R., Orús-Sanclemente, C., 2011. Analyzing the emotional outcomes of the online search behavior with search engines. Comput. Human Behav. 27, 540551. doi:10.1016/j.chb.2010.10.002

25. Gabisch, J. a, 2011. Virtual world brand experience and its impact on real world purchasing behavior. J. Brand Manag. 19, 18-32. doi:10.1057/bm.2011.29

26. Gao, Q., Rau, P.-L.P., Salvendy, G., 2009. Perception of Interactivity: Affects of Four Key Variables in Mobile Advertising. Int. J. Hum. Comput. Interact. 25, 479-505. doi:10.1080/10447310902963936

27. Gaudiosi, J., 2015. How augmented reality and virtual reality will generate $\$ 150$ billion in revenue by 2020 [WWW Document]. URL http://fortune.com/2015/04/25/augmented-realityvirtual-reality/ (accessed 11.10.15).

28. Goel, L., Prokopec, S., 2009. If you build it will they come?-An empirical investigation of consumer perceptions and strategy in virtual worlds. Electron. Commer. Res. 9, 115-134. doi:10.1007/s10660-009-9031-7

29. Hanna, R., Rohm, A., Crittenden, V.L., 2011. We're all connected: The power of the social media ecosystem. Bus. Horiz. 54, 265-273. doi:10.1016/j.bushor.2011.01.007

30. Hoffman, D.L., Novak, T.P., 1996. Marketing in Hypermedia Computer-Mediated Environments: Conceptual Foundations. J. Mark. 60, 50. doi:10.2307/1251841

31. Hoffman, D.L., Novak, T.P., 2009. Flow Online: Lessons Learned and Future Prospects. J. Interact. Mark. 23, 23-34. doi:10.1016/j.intmar.2008.10.003

32. Hsieh, J.K., Hsieh, Y.C., Tang, Y.C., 2012. Exploring the disseminating behaviors of eWOM marketing: Persuasion in online video. Electron. Commer. Res. 12, 201-224. doi:10.1007/s10660-012-9091-y

33. Huang, E., 2012. Online experiences and virtual goods purchase intention. Internet Res. 22, 252-274. doi:10.1108/10662241211235644

34. Huang, T.-L., Hsu Liu, F., 2014. Formation of augmented-reality interactive technology's persuasive effects from the perspective of experiential value. Internet Res. 24, 82-109. doi:10.1108/IntR-07-2012-0133

35. Huang, T.-L., Liao, S., 2014. A model of acceptance of augmented-reality interactive technology: the moderating role of cognitive innovativeness. Electron. Commer. Res. 15, 269-295. doi:10.1007/s10660-014-9163-2

36. Javornik, A., 2014. Classifications of Augmented Reality Uses in Marketing, in: IEEE International Symposium on Mixed and Augmented Realities 2014. Munich.

37. Jennett, C., Cox, A.L., Cairns, P., Dhoparee, S., Epps, A., Tijs, T., Walton, A., 2008. Measuring and defining the experience of immersion in games. Int. J. Hum. Comput. Stud. 66, 641-661. doi:10.1016/j.ijhcs.2008.04.004

38. Jin, S.-A.A., 2009. The Roles of Modality Richness and Involvement in Shopping Behavior in 3D Virtual Stores. J. Interact. Mark. 23, 234-246. doi:10.1016/j.intmar.2009.04.005

39. Jin, S.A., Bolebruch, J., 2009. Avatar-based advertising in Second life: The role of presence and attractiveness of virtual spokespersons. J. Interact. Advert. 10, 51-60.

40. Kaplan, A.M., Haenlein, M., 2010. Users of the world, unite! The challenges and opportunities of Social Media. Bus. Horiz. 53, 59-68. doi:10.1016/j.bushor.2009.09.003

41. Kim, J., Forsythe, S., 2008. Adoption of virtual try-on technology for online apparel shopping. J. Interact. Mark. 22, 45-59. doi:10.1002/dir.20113

42. Kim, M., Lennon, S., 2008. The Effects of Visual and Verbal Information on Attitudes and Purchase Intentions in Internet Shopping. Psychol. Mark. 25, 146-178. doi:10.1002/mar

43. Kowatsch, T., Maass, W., 2010. In-store consumer behavior: How mobile recommendation agents influence usage intentions, product purchases, and store preferences. Comput. Human Behav. 26, 697-704. doi:10.1016/j.chb.2010.01.006

44. Kozinets, R. V, de Valck, K., Wojnicki, A.C., Wilner, S.J.., 2010. Networked Narratives: Understanding Word-of-Mouth Marketing in Online Communities. J. Mark. 74, 71-89. doi: $10.1509 / j m k g .74 .2 .71$

45. Laroche, M., Habibi, M.R., Richard, M.O., Sankaranarayanan, R., 2012. The effects of social media based brand communities on brand community markers, value creation practices, brand trust and brand loyalty. Comput. Human Behav. 28, 1755-1767. doi:10.1016/j.chb.2012.04.016 
46. Lee, K.C., Chung, N., 2008. Empirical analysis of consumer reaction to the virtual reality shopping mall. Comput. Human Behav. 24, 88-104. doi:10.1016/j.chb.2007.01.018

47. Li, T., Meshkova, Z., 2013. Examining the impact of rich media on consumer willingness to pay in online stores. Electron. Commer. Res. Appl. 12, 449-461. doi:10.1016/j.elerap.2013.07.001

48. Lin, T.M.., Kuan-Yi, L., Wu, J.-J., 2012. The effects of visual information in eWOM communication. J. Res. Interact. Mark. 6, 7-26. doi:10.1007/s 13398-014-0173-7.2

49. Lister, M., Dovey, J., Giddings, S., Grant, I., Kelly, K., 2008. New media: A critical introduction. Routledge.

50. Littlejohn, S.W., Foss, K.A., 2008. Theories of Human Communication. Thomson Corporation, Belmont.

51. Liu, Y., Shrum, L.J., 2002. What is interactivity and is it always such a good thing? J. Advert. 31, 53-64.

52. Luo, X., Andrews, M., Fang, Z., Phang, C.W., 2014. Mobile targeting. Manage. Sci. 60, 1738-1756.

53. MarketsandMarkets, 2015. Augmented Reality Market worth 56.8 Billion USD by 2020 [WWW Document]. URL http://www.marketsandmarkets.com/PressReleases/augmentedreality.asp (accessed 11.16.15).

54. Merle, A., Senecal, S., St-Onge, A., 2012. Whether and How Virtual Try-On Influences Consumer Responses to an Apparel Web Site. Int. J. Electron. Commer. 16, 41-64. doi:10.2753/JEC1086-4415160302

55. Milgram, P., Kishino, F., 1994. A taxonomy of mixed reality visual displays. IEICE Trans. Inf. Syst. 77, 1321-1329.

56. Nah, F.F., Eschenbrenner, B., Dewester, D., 2011. Enhancing brand equity through flow and telepresence: A comparison of 2D and 3D virtual. MIS Q. 35, 1-19.

57. Novak, T.P., Hoffman, D.L., Duhachek, A., 2003. The Influence of Goal-Directed and Experiential Activities on Online Flow Experiences. J. Consum. Psychol. 13, 3-16. doi:10.1207/S15327663JCP13-1\&2_01

58. Novak, T.P., Hoffman, D.L., Yung, Y., 2000. Measuring Online the Customer Experience in A Structural Environments : Modeling Approach. Mark. Sci. 19, 22-42.

59. Pagani, M., Mirabello, A., 2011. The Influence of Personal and Social-Interactive Engagement in Social TV Web Sites. Int. J. Electron. Commer. 16, 41-68. doi:10.2753/JEC1086-4415160203

60. Park, E.J., Kim, E.Y., Funches, V.M., Foxx, W., 2012. Apparel product attributes, web browsing, and e-impulse buying on shopping websites. J. Bus. Res. 65, 1583-1589. doi:10.1016/j.jbusres.2011.02.043

61. Park, J., Stoel, L., Lennon, S.J., 2008. Cognitive, affective and conative responses to visual simulation: the effects of rotation in online product presentation. J. Consum. Behav. 7, 72-87. doi:10.1002/cb.237

62. Parra, J.F., Ruiz, S., 2009. Consideration sets in online shopping environments: the effects of search tool and information load. Electron. Commer. Res. Appl. 8, 252-262. doi:10.1016/j.elerap.2009.04.005

63. Pavlou, P.A., 2003. Consumer acceptance of electronic commerce: integrating trust and risk with the technology acceptance model. Int. J. Electron. Commer. 7, 101-134.

64. Pescher, C., Reichhart, P., Spann, M., 2014. Consumer Decision-making Processes in Mobile Viral Marketing Campaigns. J. Interact. Mark. 28, 43-54. doi:10.1016/j.intmar.2013.08.001

65. Preece, J., Sharp, H., Rogers, Y., 2015. Preece, Jenny, Helen Sharp, and Yvonne Rogers. Interaction Design-beyond human-computer interaction. John Wiley \& Sons.

66. Reitmayr, G., Drummond, T., 2006. Going out: robust model-based tracking for outdoor augmented reality. 2006 IEEE/ACM Int. Symp. Mix. Augment. Real. 109-118. doi:10.1109/ISMAR.2006.297801

67. Richard, M.-O., Chebat, J.-C., Yang, Z., Putrevu, S., 2010. A proposed model of online consumer behavior: Assessing the role of gender. J. Bus. Res. 63, 926-934. doi:10.1016/j.jbusres.2009.02.027

68. Rogers, Y., 2012. HCI theory: classical, modern, and contemporary. Synth. Lect. HumanCentered Informatics 5, 1-129.

69. Rohm, A.J., Gao, T. (Tony), Sultan, F., Pagani, M., 2012. Brand in the hand: A cross-market investigation of consumer acceptance of mobile marketing. Bus. Horiz. 55, 485-493. doi:10.1016/j.bushor.2012.05.004 
70. Shankar, V., Balasubramanian, S., 2009. Mobile Marketing: A Synthesis and Prognosis. J. Interact. Mark. 23, 118-129. doi:10.1016/j.intmar.2009.02.002

71. Sheth, J.N., Solomon, M.R., 2014. Extending the Extended Self in a Digital World. J. Mark. Theory Pract. 22, 123-132. doi:10.2753/MTP1069-6679220201

72. Song, J.H., Zinkhan, G.M., 2008. Determinants of Perceived Web Site Interactivity. J. Mark. 72, 99-113.

73. Steuer, J., 1992. Defining Virtual Reality: Dimensions Determining Telepresence. J. Commun. 42, 73-93.

74. Stewart, D.W., Pavlou, P.A., 2009. The effects of media on marketing communications, in: Bryant, J., Oliver, M.B. (Eds.), Media Effects: Advances in Theory and Research. Routledge, New York, pp. 362-401.

75. Ström, R., Vendel, M., Bredican, J., 2014. Mobile marketing: A literature review on its value for consumers and retailers. J. Retail. Consum. Serv. 21, 1001-1012. doi:10.1016/j.jretconser.2013.12.003

76. Su, B., 2008. Characteristics of Consumer Search On-Line: How Much Do We Search? Int. J. Electron. Commer. 13, 109-129. doi:10.2753/JEC1086-4415130104

77. Sultan, F., Rohm, A.J., Gao, T. (Tony), 2009. Factors Influencing Consumer Acceptance of Mobile Marketing: A Two-Country Study of Youth Markets. J. Interact. Mark. 23, 308-320. doi:10.1016/j.intmar.2009.07.003

78. Sundar, S.S., 2009. Media effects 2.0: Social and psychological effects of communicaiton technology, in: Nabi, R.L., Oliver, M.B. (Eds.), The SAGE Handbook of Media Processes and Effects. Sage Publications Inc, pp. 545-560.

79. Sundar, S.S., Bellur, S., Oh, J., Jia, H., Kim, H.-S., 2014. Theoretical Importance of Contingency in Human-Computer Interaction: Effects of Message Interactivity on User Engagement. Communic. Res. 1-31. doi:10.1177/0093650214534962

80. Sundar, S.S., Jia, H., Waddell, T.F., Huang, Y., 2015. Toward a theory of interactive media effects (TIME): Four models for explaining how interface features affect user psychology. Handb. Psychol. Commun. Technol. 47-86. doi:10.1002/9781118426456

81. Sundar, S.S., Xu, Q., Dou, X., 2012. Role of technology in online persuasion, in: Rodgers, S., Thorson, E. (Eds.), Advertising Theory. Routledge, pp. 355-372.

82. Van Krevelen, D.W.F., Poelman, R., 2010. A Survey of Augmented Reality Technologies , Applications and Limitations. Int. J. Virtual Real. 9, 1-20.

83. van Noort, G., Voorveld, H. a. M., van Reijmersdal, E. a., 2012. Interactivity in Brand Web Sites: Cognitive, Affective, and Behavioral Responses Explained by Consumers' Online Flow Experience. J. Interact. Mark. 26, 223-234. doi:10.1016/j.intmar.2011.11.002

84. Varadarajan, R., Srinivasan, R., Vadakkepatt, G.G., Yadav, M.S., Pavlou, P. a., Krishnamurthy, S., Krause, T., 2010. Interactive Technologies and Retailing Strategy: A Review, Conceptual Framework and Future Research Directions. J. Interact. Mark. 24, 96110. doi:10.1016/j.intmar.2010.02.004

85. Voorveld, H. a. M., Neijens, P.C., Smit, E.G., 2009. Consumers' responses to brand websites: an interdisciplinary review. Internet Res. 19, 535-565. doi:10.1108/10662240910998887

86. Xu, H., Luo, X. (Robert), Carroll, J.M., Rosson, M.B., 2011. The personalization privacy paradox: An exploratory study of decision making process for location-aware marketing. Decis. Support Syst. 51, 42-52. doi:10.1016/j.dss.2010.11.017

87. Xu, H., Oh, L. Bin, Teo, H.H., 2009. Perceived effectiveness of text vs. multimedia LocationBased Advertising messaging. Int. J. Mob. Commun. 7, 154. doi:10.1504/IJMC.2009.022440

88. Yadav, M.S., Pavlou, P. a., 2014. Marketing in Computer-Mediated Environments: Research Synthesis and New Directions. J. Mark. 78, 20-40. doi:10.1509/jm.12.0020

89. Zhou, F., Duh, H.B.-L., Billinghurst, M., 2008. Trends in augmented reality tracking, interaction and display: A review of ten years of ISMAR. 2008 7th IEEE/ACM Int. Symp. Mix. Augment. Real. 193-202. doi:10.1109/ISMAR.2008.4637362

90. Zhou, T., 2013. An empirical examination of user adoption of location-based services. Electron. Commer. Res. 13, 25-39. doi:10.1007/s10660-013-9106-3 